\title{
Pemanfaatan Daun Cengkeh (Syzygium aromaticum L.) Dalam Proses Pembuatan Virgin Coconut Oil (VCO)
}

\author{
Rosita Mangesa ${ }^{1 *}$, Irsan'. \\ ${ }^{1}$ Program Studi Pendidikan Biologi, Fakultas Keguruan dan Ilmu Pendidikan, \\ Universitas Iqra Buru \\ *E-mail: rositamangesa5@gmail.com
}

\begin{abstract}
Abstrak: Daun cengkeh merupakan bagian dari tumbuhan cengkeh yang jarang dimanfaatkan. Jika ditinjau daun cengkeh memiliki senyawa aktif yang dapat berfungsi sebagai antibakteri. Sementara VCO merupakan hasil olahan dengan bahan dasar santan kelapa, jika tidak diolah dengan baik biasanya VCO akan memiliki masa simpan yang rendah atau cepat mengalami kerusakan. Penelitian ini bertujuan untuk mengetahui kualitas dari VCO dengan penmbahan daun cengkeh dalam pengolahannya. Berdasarkan hasil penelitian terlihat bahwa, kualitas VCO dengan penambahan daun cengkeh untuk indikator kadar air dan bilangan asam lemak bebas tidak sesuai dengan standar SNI sedangkan indikator bilangan peroksida VCO dengan campuran daun cengkeh memiliki kualitas yang baik sesuai dengan standar SNI. Berdasarkan hasil penelitian terlihat bahwa kualitas VCO dengan penambahan 100 gr daun cengkeh untuk indicator kadar air dan bilangan asam lemak yaitu 2,9\% dan 0,69\% tergolong tinggi atau diatas batas standar SNI, sedangkan kualitas VCO dengan penambahan 100 gr daun cengkeh dengan indicator bilangan peroksida sebesar $0,7 \mathrm{mg}$ ek/ $\mathrm{kg}$ atau kurang dari 2 $\mathrm{mg} \mathrm{ek/kg} \mathrm{memiliki} \mathrm{kualitas} \mathrm{yang} \mathrm{baik} \mathrm{berdasarkan} \mathrm{standar} \mathrm{SNI.}$
\end{abstract}

\section{Kata Kunci: Kualitas, VCO}

\begin{abstract}
The clove leaves are part of the clove plant which rarely used, and if you look at them, the clove leaves have active compounds that can be functioned as antibacterials. Meanwhile, Virgin Coconut Oil or called VCO, is processed from coconut milk as the essential ingredient, and if it is not processed correctly, VCO will usually have a short shelf life or can be damaged quickly. This study aims to determine the quality of VCO by adding clove leaves in its processing. Based on the results of the study, it can be seen that the quality of VCO with the addition of clove leaves for the indicator of water content and the free fatty acid number is not following the Indonesian National Standard (SNI). In contrast, the indicator for the VCO peroxide number with a mixture of clove leaves has good quality according to the SNI standard. Based on the results of the study, it can be seen that the quality of VCO with the addition of 100 grams of clove leaves for indicators of water content and fatty acid numbers, namely $2.9 \%$ and $0.69 \%$, is high or
\end{abstract}


above the SNI standard limit. In comparison, the quality of VCO with the addition of 100 grams of clove leaves with indicators a peroxide value of $0.7 \mathrm{mg} \mathrm{ek} / \mathrm{kg}$ or less than $2 \mathrm{mg}$ ek/kg has good quality based on Indonesian National Standard.

\section{Keywords: Quality, VCO}

Indonesia adalah negara yang kaya dengan sumber daya alamnya, namun hal ini belum diimbangi dengan kemampuan SDMnya. Salah satu kekayaan negara Indonesia adalah rempah-rempah dan tersebar secara meluas di kepulauan Maluku seperti pala dan cengkeh. Buah pala maupun bunga cengkeh sering dimanfaat secara luas oleh masyarakat dan hal ini berbandinng terbalik dengan daun dari cengkeh maupun pala. Padahal daun cengkeh maupun pala juga mengandung senyawa yang bermanfaat bagi kehidupan.

Penelitian ini bertujuan untuk mengkaji tentang pemanfaatan daun cengkeh dalam proses pembuatan VCO apakah mampu meningkatkan kualitas VCO. Tujuan khusus dari pnelitian ini yaitu memanfaatkan daun cengkeh yang jarang dimanfatkan oleh masyarakat, bahkan tercatat bahwa daun kering dapat terkumpul sebanyak rata-rata 0,96 $\mathrm{kg} /$ pohon setiap minggunya untuk tanaman cengkeh yang berumur lebih dari 20 tahun, sedangkan tanaman yang berumur kurang dari 20 tahun dapat terkumpul sebanyak 0,46 $\mathrm{kg} /$ pohon (Rorong, 2008).

Daun cengkeh merupakan bagian dari tanaman cengkeh yang jarang sekali dimanfaatkan berbanding terbalik dengan bunga cengkeh yang lebih dominan digunakan. Dari hasil penelitian diketahui bahwa daun cengkeh juga mengandung senyawa antibakteri seperti flavonoid, fenolat, triterpenoid, tannin, fenolat, senyawa eucalyptol, $\alpha$ cardinol, kariofilen, limonene (Suhendar dkk, 2019). Senyawa flavonoid merupakan senyawa aktif yang difungsikan sebagai antibakteri, dalam hal ini diharapkan kandungan dari flavonoid pada daun cengkeh dapat menjadi pengawet alami pada VCO (Mangesa dkk, 2020; Mangesa dkk, 2019).

Virgin coconut oil (VCO) adalah produk yang dihasilkan dari daging kelapa tua yang diproduksi tanpa pemanasan dan penggunaan bahan kimia sehingga menjamin kualitas dari minyak kelapa. Pada umumnya apabila dalam VCO terdapat ikatan rangkap yang banyak maka dalam pembuatan VCO tersebut akan diikuti dengan laju oksidasi yang akan membentuk hidroproksida. Pembentukan Dekomposisi hidroproksida mengakibatkan pemutusan gugus $-\mathrm{OOH}$ dan rantai $\mathrm{C}-\mathrm{C}$ sehingga terjadinya perubahan warna, aroma, rasa, serta susunan kimia dari VCO (Iskandar and Edison, 2015).

Ciri VCO yang memiliki kualitas baik yaitu jika minyak dalam keadaan membeku akan menampakkan warna putih murni, sedangkan jika cair VCO tidak berwarna (bening). Selain itu VCO kualitas baik tidak tidak mudah tengik karena kandungan asam lemak jenuhnya tinggi sehingga tidak mudah terjadinya proses oksidasi. Hal ini berbanding terbalik dengan VCO yang memiliki kualitas rendah, maka proses ketengikan 
akan lebih cepat terjadi. Adanya ketengikan pada minyak disebabkan oleh pengaruh oksigen, mikroba yang dapat mengurangi kandungan asam lemak dalam minyak menjadi komponen lain, dan keberadaan air pada minyak secara berlebih (Aziz, dkk 2017).

Indonesia merupakan negara yang menghasilkan kelapa cukup banyak. Daing buah kelapa biasa dimanfaatkan menjadi kopra maupun santan yang kemudian diolah menjadi minyak. VCO merupakan salah satu prduk olahan berbahan dasar santan kelapa yang dalam proses pembuatannya tidak menggunakan bahan pengawet dan juga pemanasan tinggi sehingga warna dari VCO tetap jernih dan beraroma khas kelapa. VCO memiliki nilai tambah karena dapat digunakan sebagai bahan baku pembuatan kosmetik, obat-batan, makanan maupun minuman. Hal ini dikarenakan VCO mengandung sekitar $64 \%$ asam lemak jenuh rantai sedang atau medium chain saturated faty acids (MCFA) yang terdiri lebih dari 50\% asam laurat (C12), 6-7\% asam kaprat (C10), dan 8\% asam kaprilat (C8) (Dali dkk, 2015).

Saat ini banyak VCO yang telah dikembangkan dengan penambahan rempah seperti pala, salam, kemangi dan laos, dan hasilnya memenuhi standar APCC. Maluku sebagai salah satu daerah penghasil rempah lbih cenderung memanfaatkan buah, padahal daunnyapun mengandung senyawa aktif yang dapat dimanfaatkan, salah satunya daun cengkeh. Daun cengkeh mengandung komponen minyak atsiri dan komponen fenolik. Komponen fenolik merupakan antioksidan alami yang bermanfaat bagi kesehatan manusia (Rorong, 2008).

Terdapat beberapa metode dalam pembuatan VCO, yaitu metode pemanasan bertahap, metode pemancingan minyak, metode fermentasi dan metode sentrifugasi (secara mekanik). Diantara keempat metode tersebut, metode sentrifugasi merupakan metode yang lebih baik dalam menghasilkan VCO dibandingkan dengan metode pemanasan maupun metode fermentasi. Hal ini dikarenakan dengan metode sentrifugasi pemisahan terjadi secara alami tanpa melalui bantuan pemanasan maupun fermentor sehinggan rendemen yang dihasilkan lebih tinggi. Berdasarkan hasil penelitian anwar dkk (2016) bahwa kecepatan sentrifugasi dan lamanya waktu sentrifugasi akan menghasilkan mutu dari VCO lebih baik.

Proses pembuatan VCO selain secara secara sentrifugasi, pemikseran juga merupakan proses pebuatan VCO secara mekanik. Selama proes pemikseran terjadi pemisahan ikatan kimia dalam santan kelapa (Dali, 2015). Menurut Sipahelut (2011) dalam penelitiannya dengan menggunakan metode pemikseran, kualitas VCO yang dihasilkan adalah asam laurat 50,86\%, asam miristat 16,53\%, asam kaprilat 7,16\%, asam palmitate $5,92 \%$, asam oleat $6,75 \%$ dan asam lemak bebas $0,22 \%$, dan kadar asam laurat ini memenuhi standar APCC yaitu 43-53\%, serta memenuhi standar mutu VCO meburut SNI 7381 yaitu $45,1-53,2 \%$.

BIOLOGI SEL (VOL 9 NO 2 EDISI JUL-DES 2020 ISSN 2252-858X/E-ISSN 2541-1225) PAGE 186 


\section{METODE PENELITIAN}

Tahapan awal dalam penelitian ini yaitu penyiapan daun cengkeh. Daun cengkeh yang telah dipetik, dicuci bersih, diparut kemudian dikeringanginkan tidak dibawah sinar matahari langsung. Menyiapkan krim santan yang merupakan hasil modifikasi dari penelitian (Dali dkk, 2015) dan (Nuryati dkk, 2013)

Sebanyak 15 buah daging kelapa tua dicuci bersih dan ditimbang lalu diparut dengan mesin parut. Hasil parutan ditambahkan air sebanyak 4 L dan diremas-remas selama 15-20 menit hingga menjadi santan dan ditambahkan dengan daun cengkeh sebanyak 100 gr. Santan kelapa disimpan dalam wadah transparan selama kurang lebih 2 jam sampai terbentuk dua lapisan. Lapisan atas adalah krim santan dan lapisan bawah adalah skim yang bercampur air. Kedua lapisan kemudian dipisahkan, dan lapisan kirm diambil sementara lapisan skim dibuang. Krim santan kemudian dimixer dengan kecepatan maksimal selama 1 jam dan didiamkan selama 20 jam hingga terbentuk tiga lapisan yaitu lapisan atas (VCO), lapisan kedua (blondo), dan lapisan ketiga (air). Tahap selanjutnya ketiga lapisan dipisahkan, lapisan atas VCO diambil dipindahkan dibotol yang jernih melalui proses penyaringan.

Selanjutnya tahapan analisis kualitas VCO

\section{Uji Kadar Air}

Sebanyak 5 gr VCO ditimbang dalam cawan yag sudah diketahui bobot konstannya. Selanjutnya VCO dipanaskan dalam oven pda suhu $105^{\circ} \mathrm{C}$ selama 1 jam. Selanjutnya VCO didinginan dalam desikator selama 30 menit. Setelah dingin VCO ditimbang kembali dengan cawan, peristiwa ini diulang kembali hingga diperoleh bobot konstan, kadar air VCO ditentu kan dengan rumus:

Kadar air $=\frac{m 2-m 3}{m 2-m l} \times 100 \%$

\section{Uji Bilangan Peroksida}

Sebanyak 5 gr VCO dimasukkan dalam labu Erlenmeyer $250 \mathrm{ml}$. Selanjutnya 10 $\mathrm{ml}$ kloroform ditambakan kedalam labu lalu diaduk denganmagnetik stirrer selama 5 menit. Setelah itu $15 \mathrm{ml}$ asam asetat glasial dan $1 \mathrm{ml}$ larutan kalium iodide ditambahkan kedalam labu. Segera setelah iitu labu ditutup rapat dan diaduk dengan magnetic stirrer selama 5 menit ditempat gelap pada suhu kamar. Selanjutnya $75 \mathrm{ml}$ aquadest ditambahkan kedalam labu lalu diaduk kembali dengan magnetic stirrer selama 5 menit. Kemudian sampel VCO dititrasi dengan larutan standar natrium tiosulfat 0,01 N dengan larutan kanji 0,5\% sebagai indicator. Prosedur ini dilaukan duplo dengan penetapan blangko. Baingan peroksida dihitung dengan rumus:

$$
\text { Bilangan peoksida }=\frac{(V 1-V 0) \times N}{m} \times 1000
$$

\section{Uji Asam Lemak Bebas}

Sebanyak 5 gr VCO dimasukan dalam labu Erlenmeyer $250 \mathrm{ml}$ selanjutnya $25 \mathrm{ml}$ etanol 95\% dan 3 tetes indicator PP (Phenoftalein) ditmbahkan kedalam labu. Sampel 
VCO dititrasi dengan larutan standar $\mathrm{KOH} 0,1 \mathrm{~N}$ sehingga terbentuk warna merah mudah tetap (tidak berubah selama 15 menit). Prosedur ini dilakukan duplo dengan penetapan blanko. Kadar asam lemak bebas VCO dihitung dengan rumus:

Asam lemak bebas $=\frac{V \times N \times 205}{m \times 10}$

\section{HASIL DAN PEMBAHASAN}

Penelitian ini bertujuan untuk menentukan kualitas dari VCO maka dilakukan uji kadar air, angka peroksida, dan bilangan asam, dari VCO dengan campuran daun cengkeh. Berdasarkan hasil uji analisa laboraturium, kandungan kadar air, angka peroksida, dan bilangan asam dari VCO dengan campuran daun cengkeh sebagai berikut: Kadar Air VCO Dengan Penambahan Daun Cengkeh

Pengaruh daun cengkeh terhadap kadar air VCO dapat dilihat pada tabel 1. Pada tabel dibawah ini terlihat bahwa, VCO dengan penambahan daun cengkeh memiliki kadar air berkisar antara 2,73\% hingga 3,17\% pada ulangan 1 dan 2 .

Tabel 1. Hasil Analisa kadar air VCO dengan penambahan daun cengkeh:

\begin{tabular}{|l|l|l|l|l|}
\hline No & Ulangan & Berat Sampel & Berat Air & Kadar Air \\
\hline 1. & I & 10,1679 & 0,2783 & 2,7370 \\
\hline 2. & II & 10,4953 & 0,3279 & 3,1242 \\
\hline \multicolumn{3}{|c|}{ TOTAL RATA-RATA } & 2.9306 \\
\hline
\end{tabular}

Dari hasil analisa laboraturium terlihat bahwa kadar air dari VCO dengan penambahan daun cengkeh tidak memenuhi Standar Nasional Indonesia (SNI) No. 731 tahun 2008 yang telah ditetapkan kadar air VCO maksimal 0,2\% (BSN, 2008). Adanya total kadar air dengan rata-rata sebesar 2,9\% disebabkan akrena adanya kontak langsung dengan air saat proses pembuatan santan. Penggunaan air yang banyak saat pembuatan santan sebagai bahan baku utama VCO akan berdampak pada kadar air dalam minyak. Banyaknya kadar air dalam minyak VCO dapat menyebabkan percepatan proses ketengikan. Hal ini sejalan dengan penelitian Widjaja, 2015 bahwa kualitas dari VCO dinilai dari jumlah kadar air didalamnya. Kadar air yang terdapat didalam VCO disebabkan karena adanya kontak dengan air.

\section{Angka Peroksida VCO Dengan Penambahan Daun Cengkeh}

Berikut merupakan tabel hasil analisa angka peroksida pada VCO degan penambahan daun cengkeh.

Tabel 2. Hasil Analisa kadar air VCO dengan penambahan daun cengkeh:

\begin{tabular}{|l|l|l|l|l|}
\hline No & Ulangan & Berat Sampel & M1 Tio 0,01 N & Angka Peroksida \\
\hline 1. & I & 5,2143 & 0,35 & 0,6712 \\
\hline 2. & II & 5,1873 & 0,30 & 0,7710 \\
\hline \multicolumn{4}{|l|}{ TOTAL RATA-RATA } & 0.7211 \\
\hline
\end{tabular}

Berdasarkan tabel 2 diatas terlihat bahwa angka peroksida VCO dengan penambahan daun cengkeh memiliki nilai rata-rata berkisar $0,7 \mathrm{mg} \mathrm{ek} / \mathrm{kg}$. Berdasarkan

BIOLOGI SEL (VOL 9 NO 2 EDISI JUL-DES 2020 ISSN 2252-858X/E-ISSN 2541-1225) PAGE 188 
Standar Nasional Indonesia (SNI) bahwa minyak yang berkualitas apabila memiliki nilai bilangan peroksida kurang dari $2 \mathrm{mg}$ ek/kg. maka dari hasil yang diperoleh dapat disimpulkan bahwa berdasarkan indikator bilangan peroksida VCO dengan penambahan daun cengkeh memiliki kualitas yang baik berdasarkan standar SNI. Hal ini disebabkan karena kontak VCO dengan penambahan daun cengkeh terhadap udara cenderung kurang, selain itu karena adanya Senyawa 3-Allyl-6-methoxyphenol-eugenol sebesar $57,04 \%$, Selain itu mengandung senyawa 3-Allyl-6-methoxyphenol-Eugenol, pucuk cengkeh mengandung senyawa lain diantaranya caryophyllene; 1,4,7-cycloundecatriene; 1,5,9,9-tetramethyl; dan eugenol acetate yang mana senyawa-senyawa tersebut diketahui memiliki manfaat dalam bidang pengobatan dan antimikroba (BSN, 2008., Suhendar dkk, 2019).

\section{Bilangan Asam}

Bilangan asam pada VCO dengan penambahan daun cengkeh dapat dinyatakan sebagai \% FFA yang disesuaikan dengan SNI, yang mana modifikasi diakukan pada larutan baku sekunder $\mathrm{KOH}$ yang telah distandarisasi menggunakan larutan baku primer asam oksalat. Berikut merupakan tabel hasil analisa angka Bilangan Asam pada VCO dengan penambahan daun cengkeh.

Tabel 2. Hasil Analisa Kadar Air VCO dengan Penambahan Daun Cengkeh

\begin{tabular}{|l|l|l|l|l|}
\hline No & Ulangan & Berat Sampel & M1 KOH 0,01 N & Angka Peroksida \\
\hline 1. & I & 5,6516 & 1,185 & 0,6710 \\
\hline 2. & II & 5,6917 & 2,00 & 0,7203 \\
\hline \multicolumn{3}{|c|}{ TOTAL RATA-RATA } & 0.6956 \\
\hline
\end{tabular}

Berdasarkan tabel diatas, terlihat bahwa terlihat bahwa bilangan asam VCO dengan penambahan daun cengkeh memiliki total rata-rata $0,69 \%$ hal ini masuk tergolong tinggi diatas batas yang ditentukan oleh Badan Standar Nasional Indonesia (BSN) yaitu maksimum sebesar $0,2 \%$.

Tingginya kandungan asam lemak bebas dapat diakibatkan karena banyaknya komponen trigliserida penyusun minyak (VCO) yang mengalami hidrolisis yang disebabkan oleh pengolahan yang tidak benar, serta adanya kandungan air yang berlebih pada VCO yang menyebabakan penurunan kualitas dari VCO (Suaniti dkk, 2014).

\section{KESIMPULAN}

Berdasarkan hasil penelitian terlihat bahwa kualitas VCO dengan penambahan $100 \mathrm{gr}$ daun cengkeh untuk indicator kadar air dan bilangan asam lemak yaitu 2,9\% dan 0,69\% tergolong tinggi atau diatas batas standar SNI, sedangkan kualitas VCO dengan penambahan 100 gr daun cengkeh dengan indicator bilangan peroksida sebesar $0,7 \mathrm{mg}$ $\mathrm{ek} / \mathrm{kg}$ atau kurang dari $2 \mathrm{mg}$ ek/kg memiliki kualitas yang baik berdasarkan standar SNI 


\section{DAFTAR PUSTAKA}

Arditiani N.K., Susanti N. M.P., Larasanti L.P.F. (2015). Rendemen VCO (Virgin Coconut Oil) Yang Diperoleh Dengan Penmabahan Enzim Papain Dan Bromealin. Jurnal Farmasi Udayana Volume IV, Nomor 2.

BSN. 2008. Standar Nasional Indonesia (SNI) Minyak Kelapa Virgin (VCO). Jakarta

Dali Arniah., L. M. La Harimu., Simbiti Cinong. (2015). Pengaruh Kecepatan Putar Pengadukan Dan Waktu Pendiaman Terhadap Rendemen Dan Kualitas Minyak Kelapa Murni (VCO). Jurusan PMIPA, FKIP, Universitas Halu Oleo, Kendari. Jayanudin. (2011). Komposisi Kimia Minyak Atsiri Daun Cengkeh Dari Proses Penyulingan Uap. Jurnal Teknik Kimia Indonesia. Vol 10. No 1

Mangesa Rosita., Aloatuan Febiayau. (2019). Efektifitas dan Kandungan Fraksi Aktif Metanol Daun Sirih Hijau (Piper Betle L) Sebagai Antibakteri Salmonela typhi. Biosfer, Jurnal Tadris Biologi. Volume 10(1)

Mangesa Rosita., Irsan. (2020). Efektifitas Fraksi Aktif Metanol Daun Sirih Merah (Piper crocatum) Yang Berpotensi Sebagai Antibakteri Salmonela typhi, Uniqbu Journal of Exact Sciences (UJES), Volume 1(2).

Nuryanti Siti., Rahmawati Sitti., U.B Siti Nadira. (2013). Pemanfaatan Daun Polado (Agave sp) Dalam Proses Pembuatan Virgin Coconut Oil (VCO). Jurnal Akademika Kim. Vol.2 No 2.

Rorong Johnly Alfrets. (2008). Uji Aktifitas Antioksidan Dari Daun Cengkeh (Eugenia Carryophyllus) Dengan Metode DPPH. Chem. Prog. Vol. 1 No. 2

Sipahelut G. (2011). Sifat Kimia Dan Organoleptik Virgin Coconut Oil Hasil Fermentasi Menggunakan Teknik Pemecah Rantai. Ambon Program Studi Teknologi Hasil Pertanian Fakultas Pertanian Universitas Pattimura.

Suaniti Ni. M., Manurung Manuntun., Hartasiwi Nadya. (2014). Uji Sifat Virgin Coconut Oil (VCO) Hasil Ekstraksi Enzimatis Terhadap Berbagai Produk Minyak Kelapa Hasil Publikasi

Suhendar Usep., Sogandi. (2019). Identifikasi Senyawa Aktif Ekstrak Daun Cengkeh Sebagai Inhibitor Streptococcus muntans. Al-Kauniyah: Jurnal Biologi, Volume 12, No 2. 